\title{
Peritoneal Laceration
}

National Cancer Institute

\section{Source}

National Cancer Institute. Peritoneal Laceration. NCI Thesaurus. Code C50695.

A cut or tear of the peritoneum. 